\title{
Hemodynamic and ventilatory responses during exercise in chronic thromboembolic disease
}

\author{
Coen van Kan, MD, ${ }^{a}$ Mart N. van der Plas, PhD, ${ }^{a, b}$ Herre J. Reesink, MD, PhD, ${ }^{a, b, c}$ \\ Reindert P. van Steenwijk, MD, PhD, ${ }^{\mathrm{b}}$ Jaap J. Kloek, MD, ${ }^{\mathrm{d}}$ Robert Tepaske, MD, PhD, \\ Peter I. Bonta, MD, PhD, ${ }^{b}$ and Paul Bresser, MD, $\mathrm{PhD}^{\mathrm{a}, \mathrm{b}}$
}

\begin{abstract}
Background: Patients with chronic thromboembolic disease (CTED) may suffer from exercise intolerance without pulmonary hypertension at rest. Pulmonary endarterectomy (PEA) for symptomatic CTED results in improvement of symptoms and quality of life. Neither the pathophysiology of the exercise limitation nor the underlying mechanisms of the PEA-induced improvement have been studied previously.
\end{abstract}

Objectives: We studied hemodynamic and ventilatory responses upon exercise in 14 patients with CTED. After 1 year, we studied the underlying physiologic mechanisms of the PEA-induced symptomatic improvement.

Methods: Cardiopulmonary exercise testing (CPET) was performed during right heart catheterization, and noninvasive CPET was performed 1 year postoperatively.

Results: During exercise, we observed abnormal pulmonary vascular responses, that is, a steep mean pulmonary artery pressure/cardiac output $(2.7 \pm 1.2 \mathrm{~mm}$ $\left.\mathrm{Hg} \cdot \min \cdot \mathrm{L}^{-1}\right)$, and low pulmonary vascular compliance $(2.8 \pm 1.1 \mathrm{~mL} \cdot \mathrm{mm}$ $\mathrm{Hg}^{-1}$ ); mean pulmonary artery pressure/cardiac output slope correlated with dead-space ventilation $(\mathrm{r}=0.586 ; P=.028)$ and ventilatory equivalents for carbon dioxide slope $(\mathrm{r}=.580 ; P=.030)$. Postoperatively, the improvement observed in exercise capacity was related to improvements in CPET-derived parameters pointing to restoration of right ventricle stroke volume response (oxygen pulse: $11.7 \pm 3.1$ to $13.3 \pm 3.3 ; P=.027$; heart rate response: $80.9 \pm 12.4$ to $72.0 \pm 5.7 ; P=.003$ ); and, indicating improved ventilatory efficiency, the ventilatory equivalents for carbon dioxide slope decreased from $38.2 \pm 3.6$ to $32.8 \pm 7.0(P=.014)$.

Conclusions: Patients with CTED showed an abnormal pulmonary vascular response to exercise and a decreased ventilatory efficiency. Responses after PEA point to restoration of right ventricle stroke volume response and ventilatory efficiency. (J Thorac Cardiovasc Surg 2016;152:763-71)

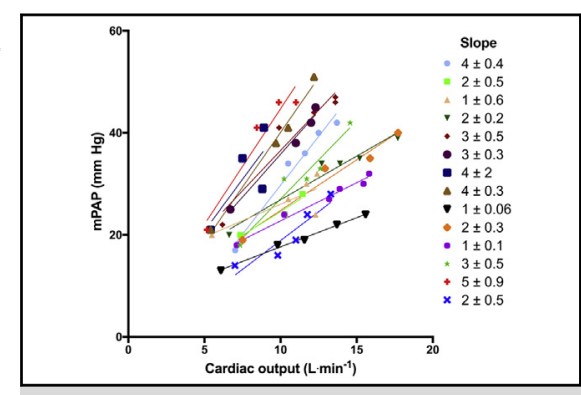

Mean pulmonary artery pressure and cardiac output relation of the 14 patients with chronic thromboembolic disease with corresponding slopes.

\section{Central Message}

Patients with chronic thromboembolic disease show abnormal pulmonary vascular response to exercise and decreased ventilatory efficiency. Responses after pulmonary endarterectomy point to restoration of stroke volume response and ventilatory efficiency.

\section{Perspective}

Patients with chronic thromboembolic disease suffer from exercise intolerance without pulmonary hypertension at rest. Surgery is not absolutely mandatory; and, current guidelines do not formally address these patients. Pulmonary endarterectomy for chronic thromboembolic disease results in improvement of symptoms and quality of life. Neither the pathophysiology of the exercise limitation nor the underlying mechanisms of the pulmonary endarterectomyinduced improvement were studied before.

See Article page 669.

See Editorial Commentaries page 675 and 771
Chronic thromboembolic pulmonary hypertension (CTEPH) results from incomplete resolution of the vascular obstruction associated with pulmonary embolism. ${ }^{1} \mathrm{CTEPH}$ is a life-

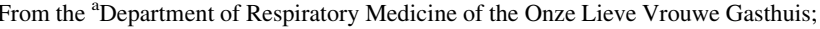
Departments of ${ }^{\mathrm{b}}$ Respiratory Medicine of the Academic Medical Center, ${ }^{\mathrm{d} C}$ Cardiothoracic surgery of the Academic Medical Center, and ${ }^{\mathrm{e}}$ Intensive Care Medicine of the Academic Medical Center, University of Amsterdam, Amsterdam; and ${ }^{\mathrm{c}}$ Department of Respiratory Medicine of the Antonius Ziekenhuis, Nieuwegein, The Netherlands.
}

Received for publication Oct 22, 2015; revisions received May 22, 2016; accepted for publication May 31, 2016; available ahead of print June 29, 2016. threatening ${ }^{2}$ but potentially curable form of pulmonary hypertension $(\mathrm{PH}){ }^{1,3}$ If left untreated, however, the prognosis is poor and proportional to the degree of $\mathrm{PH}^{2,3}$ Pulmonary

\footnotetext{
Address for reprints: Coen van Kan, MD, Onze Lieve Vrouwe Gasthuis Oosterpark 9 1091 AC Amsterdam; PO Box 95500, 1090 HM Amsterdam, The Netherlands (E-mail: coenvkan@gmail.com).

$0022-5223 / \$ 36.00$

Copyright (C) 2016 by The American Association for Thoracic Surgery http://dx.doi.org/10.1016/j.jtcvs.2016.05.058
} 


$\begin{array}{ll}\text { Abbreviations and Acronyms } \\ \mathrm{CO} & =\text { cardiac output } \\ \mathrm{CPET} & =\text { cardiopulmonary exercise testing } \\ \mathrm{CTED} & =\text { chronic thromboembolic disease } \\ \mathrm{CTEPH} & =\text { chronic thromboembolic pulmonary } \\ & \text { hypertension } \\ \mathrm{CTE}(\mathrm{PH}) & =\text { chronic thromboembolic disease with } \\ & \text { and without pulmonary hypertension } \\ \mathrm{HR} & =\text { heart rate } \\ \mathrm{mPAP} & =\text { mean pulmonary artery pressure } \\ \mathrm{O}_{2} & =\text { oxygen } \\ \mathrm{PCWP} & =\text { pulmonary capillary wedge pressure } \\ \mathrm{PEA} & =\text { pulmonary endarterectomy } \\ \mathrm{PH} & =\text { pulmonary hypertension } \\ \mathrm{PVR} & =\text { pulmonary vascular resistance } \\ \mathrm{RV} & =\text { right ventricle } \\ \mathrm{SV}^{\mathrm{N}} & =\text { stroke volume } \\ \mathrm{V}^{\prime} \mathrm{CO} & =\text { carbon dioxide production } \\ \mathrm{V}_{\mathrm{d}} / \mathrm{V}_{\mathrm{t}} & =\text { dead-space ventilation } \\ \mathrm{V}_{\mathrm{E}}^{\prime} & =\text { minute ventilation } \\ \mathrm{V}_{\mathrm{E}}^{\prime} / \mathrm{V}^{\prime} \mathrm{CO}_{2}= & \text { ventilatory equivalents for carbon } \\ \mathrm{V}^{\prime} \mathrm{O}_{2} & =\text { dioxide } \\ \end{array}$

Scanning this QR code will take you to the article title page.

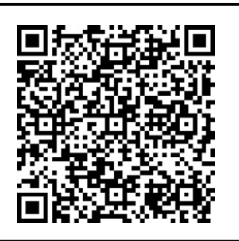

endarterectomy (PEA) represents the therapy of choice in patients with surgically accessible thrombi. PEA improves and in many cases (near) normalizes pulmonary hemodynamics, which is associated with improvements in functional status, exercise capacity, and long-term survival. ${ }^{4,5}$

A subgroup of patients with chronic thromboembolic obstruction of the pulmonary arteries present with exercise intolerance without signs of $\mathrm{PH}$ at rest. ${ }^{3,6}$ Because the long-term prognosis in these patients with symptomatic chronic thromboembolic disease (CTED) appears excellent, ${ }^{2}$ surgery is not absolutely mandatory, and current guidelines do not formally address these patients. Nevertheless, given their symptomatology and favorable perioperative risk profile, in most expert centers PEA is offered to these patients, resulting in significant improvement in symptoms and quality of life in most. ${ }^{3,7}$

The exercise limitation in patients with CTED may be the consequence of a circulatory impairment and/or increased dead-space ventilation $\left(\mathrm{V}_{\mathrm{d}} / \mathrm{V}_{\mathrm{t}}\right){ }^{8}$. So far, neither the pathophysiology of the exercise limitation nor the underlying mechanisms of the PEA-induced symptomatic improvement have been studied systematically. Therefore, we characterized the pathophysiology of the exercise limitation observed in 14 patients with symptomatic CTED without PH at rest and studied the effect of PEA on clinical and physiological outcome 1 year postoperatively.

\section{METHODS}

All measurements were performed as part of the routine clinical practice and the data used anonymized. Further processing of the data was conducted in accordance with the principles of the Declaration of Helsinki. The study was reviewed by our Institutional Review Board. It concluded that the Medical Research Involving Human Subjects Act (Wet Medisch-wetenschappelijk Onderzoek) did not apply to this study, and therefore the study was exempt from further review.

All studied patients had angiographic evidence for proximal chronic thromboembolic occlusion of at least 2 lobes and they had received oral anticoagulation therapy for at least 3 months before referral to our hospital. Diagnostic work-up including noninvasive cardiopulmonary exercise testing (CPET) was performed as described. ${ }^{5,9}$ In all patients, left ventricular systolic and/or diastolic dysfunction at rest was ruled out by transthoracic echocardiography. Patients with CTED were evaluated further with exercise testing during right heart catheterization to determine hemodynamic changes during exercise. Exercise-induced $\mathrm{PH}$ was defined according to at that time operative guidelines as mean pulmonary artery pressure (mPAP) exceeding $30 \mathrm{~mm} \mathrm{Hg}$ on exercise. ${ }^{10}$ Patients who subsequently underwent PEA were re-evaluated routinely after 1 year.

\section{Cardiopulmonary Exercise Testing}

Symptom limited CPET was performed with a cycle ergometer in the semi-upright position and assessed as described. ${ }^{11}$ Continuous measurements were made of minute ventilation $\left(\mathrm{V}^{\prime}{ }_{\mathrm{E}}\right)$, oxygen consumption $\left(\mathrm{V}^{\prime} \mathrm{O}_{2}\right)$, carbon dioxide production $\left(\mathrm{V}^{\prime} \mathrm{CO}_{2}\right)$, heart rate $(\mathrm{HR})$, blood pressure, and electrocardiography. Workload was increased by 5 to 15 Watts, depending on the predicted maximum exercise capacity and in such a way that maximal effort was attained within 10 to 15 minutes. HR reserve was calculated by subtracting the resting HR from the peak HR.

\section{Exercise Hemodynamic Assessment}

CPET during right heart catheterization was performed in the intensive care unit and supervised by a senior intensive care specialist. A Swan-Ganz catheter was placed via the jugular vein into the pulmonary artery. A catheter was placed into the radial artery for arterial blood sampling. After the patient had 5 minutes of rest, a submaximal exercise protocol was performed at 5-minute intervals at 25, 50, and 75 Watts. Additional intervals were performed depending on the preassessed maximum CPET-assessed exercise capacity, in such way that patients exercised below their predetermined anaerobic threshold.

Pulmonary hemodynamics, $\mathrm{V}_{\mathrm{E}}^{\prime}, \mathrm{V}^{\prime} \mathrm{O}_{2}, \mathrm{~V}^{\prime} \mathrm{CO}_{2}$, and $\mathrm{HR}$ were determined at steady state during the last 2 minutes of each interval. Also, arterial and mixed venous blood samples were taken to calculate cardiac output (CO) with the Fick equation $\left[\mathrm{CO}=\mathrm{V}^{\prime} \mathrm{O}_{2} \times\right.$ (arterial-mixed venous oxygen content difference)]. Pulmonary capillary wedge pressure (PCWP) was measured at the end of each exercise interval. Pulmonary vascular resistance (PVR) was calculated as [(mPAP-PCWP)/CO]. The mPAP-CO slopes were determined, ${ }^{12}$ and pulmonary vascular compliance was calculated by dividing the stroke volume (SV) by the pulse pressure $[\mathrm{SV} /$ (systolic pulmonary arterial pressure - diastolic pulmonary arterial pressure)]. ${ }^{13} \quad \mathrm{~V}_{\mathrm{d}} / \mathrm{V}_{\mathrm{t}}$ was calculated with the Bohr-Enghoff equation $\left[\mathrm{V}_{\mathrm{d}} / \mathrm{V}_{\mathrm{t}}=\left(\mathrm{P}_{\text {arterial }} \mathrm{CO}_{2}-\mathrm{P}_{\text {expired }} \mathrm{CO}_{2}\right) / \mathrm{P}_{\text {arterial }} \mathrm{CO}_{2}\right]$, where $\mathrm{P}_{\text {arterial }} \mathrm{CO}_{2}$ is the arterial carbon dioxide pressure and $\mathrm{P}_{\text {expired }} \mathrm{CO}_{2}$ is the expired carbon dioxide pressure. 
TABLE 1. Baseline characteristics

\begin{tabular}{|c|c|}
\hline Value & $\mathbf{n}=14$ \\
\hline \multicolumn{2}{|l|}{ Baseline characteristics } \\
\hline Age, y (range) & $48 \pm 16(18-74)$ \\
\hline Male/female, $\mathrm{n}$ & $4 / 10$ \\
\hline Height, $\mathrm{m}$ & $1.7 \pm 0.1$ \\
\hline Weight, kg & $81 \pm 17$ \\
\hline BSA, $\mathrm{m}^{2}$ & $1.9 \pm 0.2$ \\
\hline $\mathrm{BMI}, \mathrm{kg} / \mathrm{m}^{2}$ & $28 \pm 6$ \\
\hline \multicolumn{2}{|l|}{ Pulmonary function } \\
\hline FVC, $\%$ predicted & $104 \pm 12$ \\
\hline $\mathrm{FEV}_{1}, \%$ predicted & $98 \pm 11$ \\
\hline $\mathrm{FEV}_{1} / \mathrm{FVC}$ & $0.78 \pm 0.10$ \\
\hline TLCO, $\%$ predicted & $65 \pm 9$ \\
\hline TLCO/VA, \% predicted & $80 \pm 11$ \\
\hline \multicolumn{2}{|l|}{ Functional parameters } \\
\hline 6-MWD, m & $529 \pm 62$ \\
\hline BORG at rest & $1.2 \pm 1.2$ \\
\hline BORG after exercise & $3.6 \pm 1.3$ \\
\hline Heart rate at rest (6-MWT), bpm & $81 \pm 13$ \\
\hline Heart rate at end exercise (6-MWT), bpm & $122 \pm 22$ \\
\hline $\mathrm{SaO}_{2}$ at rest (6-MWT), \% & $97 \pm 2$ \\
\hline $\mathrm{SaO}_{2}$ at end exercise (6-MWT), \% & $91 \pm 7$ \\
\hline NYHA functional class II/III, n & $11 / 3$ \\
\hline \multicolumn{2}{|c|}{$\begin{array}{l}\text { Data presented as mean } \pm \text { standard deviation or otherwise stated. } B S A \text {, Body surface } \\
\text { area; } B M I \text {, body mass index; } F V C \text {, forced vital capacity; } F E V_{1} \text {, forced expiratory } \\
\text { volume in } 1 \mathrm{~s} ; T L C O \text {, transfer factor for carbon monoxide; } V A \text {, alveolar volume; } \\
6-M W D, 6-\text {-minute walk distance; } B O R G \text {, BORG score of perceived dyspnoea; } \\
6-M W T \text {, 6-minute walk test; } b p m \text {, beats per minute; } \mathrm{SaO}_{2} \text {, transcutaneous oxygen } \\
\text { saturation; } N Y H A \text {, New York Heart Association. }\end{array}$} \\
\hline
\end{tabular}

\section{Statistical Analysis}

Analyses were performed with the SPSS statistical package (SPSS 11.5; Chicago, Ill). Baseline results are expressed as mean \pm standard deviation or median \pm interquartile range for skewed data, whereas results for pre-post comparison are expressed as mean \pm standard error of the mean. For normally distributed variables, a Student paired $t$ test was used to analyze the effect of PEA. Wilcoxon matched pairs signed ranks test was used to compare skewed data. Spearman rho correlation test was used to assess correlations between parameters and was tested for 2-sided significance.

\section{RESULTS}

\section{Patient Characteristics and Baseline Noninvasive CPET}

Baseline characteristics of the patients are summarized in Table 1. All patients were functionally classified as New York Heart Association functional class II $(\mathrm{n}=11)$ and III $(\mathrm{n}=3)$, respectively. Vital capacity was normal without signs of airway obstruction. Mean transfer capacity for carbon monoxide was slightly reduced; however, it was corrected for the alveolar volume within normal limits. On average, $\mathrm{V}_{\mathrm{d}} / \mathrm{V}_{\mathrm{t}}$ at rest appeared increased.

Baseline noninvasive CPET (Table 2) showed a $\mathrm{V}^{\prime} \mathrm{O}_{2}$-peak within normal limits, that is, $>85 \%$ of predicted, in all but 3 patients. Mean ventilatory reserve was within normal limits, that is, $>15 \%$, in all but 1 patient. Mean HR reserve was low, and 6 patients had a decreased HR reserve, that is, $<15$ beats per minute. Three patients reached both their ventilatory and
TABLE 2. Preoperative noninvasive CPET characteristics

\begin{tabular}{|c|c|c|}
\hline Noninvasive CPET parameters & $\mathrm{n}=\mathbf{1 4}$ & Normal value \\
\hline Maximal workload, Watts & $129 \pm 36$ & \\
\hline $\mathrm{V}^{\prime} \mathrm{O}_{2}$ peak, $\mathrm{L} \cdot \mathrm{min}^{-1}$ & $1.8 \pm 0.4$ & \\
\hline $\mathrm{V}^{\prime} \mathrm{O}_{2}$ peak, $\%$ predicted & $96 \pm 16$ & $\geq 85 \%$ of predicted \\
\hline $\mathrm{V}^{\prime} \mathrm{O}_{2} @ \mathrm{AT}, \mathrm{L} \cdot \mathrm{min}^{-1}$ & $1.3 \pm 0.3$ & \\
\hline $\mathrm{V}^{\prime} \mathrm{O}_{2} @ \mathrm{AT}, \%$ of $\mathrm{V}^{\prime} \mathrm{O}_{2}$ peak & $66 \pm 10$ & $\begin{array}{l}\geq 40 \% \text { of predicted } \\
\mathrm{V}^{\prime} \mathrm{O}_{2 \max }\end{array}$ \\
\hline Maximal ventilation, $\mathrm{L} \cdot \min ^{-1}$ & $90 \pm 15$ & \\
\hline Ventilatory reserve, $\%$ & $23 \pm 11$ & $\geq 15 \%$ \\
\hline Maximal heart rate, bpm & $161 \pm 23$ & \\
\hline Heart rate reserve, bpm & $10 \pm 23$ & \\
\hline Heart rate response, bpm & $82 \pm 15$ & \\
\hline $\mathrm{V}_{\mathrm{E}}^{\prime} / \mathrm{V}^{\prime} \mathrm{CO}_{2} @ \mathrm{AT}$ & $39 \pm 5$ & $\leq 34$ \\
\hline $\mathrm{V}_{\mathrm{E}}^{\prime} / \mathrm{V}^{\prime} \mathrm{CO}_{2}$ at peak & $48 \pm 7$ & $\leq 39$ \\
\hline $\mathrm{V}_{\mathrm{E}}^{\prime} / \mathrm{V}^{\prime} \mathrm{CO}_{2}$ slope & $39 \pm 5$ & $\leq 26.0$ \\
\hline Peak $\mathrm{O}_{2}$ pulse, $\mathrm{mL} \cdot$ beat $^{-1}$ & $11 \pm 3$ & \\
\hline Peak $\mathrm{O}_{2}$ pulse, $\%$ predicted & $100 \pm 19$ & $\geq 80 \%$ of predicted \\
\hline$\Delta \mathrm{V}^{\prime} \mathrm{O}_{2} / \Delta$ Wattage, $\mathrm{L} \cdot \mathrm{min} \cdot \mathrm{Watt}^{-1}$ & $10 \pm 2$ & $10 \mathrm{~L} \cdot \min \cdot \mathrm{Watt}^{-1}$ \\
\hline $\mathrm{SaO}_{2}$ peak, $\%$ & $92 \pm 5$ & $\geq 95 \%$ \\
\hline RER & $1.03 \pm 0.09$ & \\
\hline
\end{tabular}

Data presented as mean \pm standard deviation; normal (cut-off) values according to Wasserman et $\mathrm{al}^{14}$ and reported values in healthy individuals. CPET, Cardiopulmonary exercise testing; $V^{\prime} O_{2}$ peak, peak oxygen consumption; $V^{\prime} O_{2} @ A T$, oxygen consumption at the anaerobic threshold; $V^{\prime} O_{2 \max }$, maximal oxygen consumption; bpm, beats per minute; $V_{E}^{\prime}$, minute ventilation; $V^{\prime} \mathrm{CO}_{2}$, carbon dioxide production; $V_{E}^{\prime} / V^{\prime} C O_{2} @ A T$, ventilatory equivalent for carbon dioxide at the anaerobic threshold; $\mathrm{O}_{2}$ pulse, oxygen pulse; $\Delta V^{\prime} \mathrm{O}_{2} / \Delta$ Wattage, slope of the oxygen consumption and workload relation; $\mathrm{SaO}_{2}$ peak, transcutaneous oxygen saturation at peak exercise level; RER, respiratory exchange ratio.

circulatory limits, and 4 patients failed to reach their (predicted) physiological limits during exercise. ${ }^{14}$ On average, $\mathrm{V}^{\prime} \mathrm{O}_{2}$ /wattage was normal with normal $\mathrm{V}^{\prime} \mathrm{O}_{2}$ at the anaerobic threshold, indicative for a normal aerobic work efficiency and a normal physical condition; however, the ventilatory equivalents for carbon dioxide $\left(\mathrm{V}_{\mathrm{E}}^{\prime} / \mathrm{V}^{\prime} \mathrm{CO}_{2}\right)$ at the anaerobic threshold and at peak exercise were elevated. In line, the slope of the $\mathrm{V}_{\mathrm{E}}^{\prime} / \mathrm{V}^{\prime} \mathrm{CO}_{2}$ relation was increased. Mean oxygen $\left(\mathrm{O}_{2}\right)$ pulse was normal. One of the 3 patients with a reduced $\mathrm{V}^{\prime} \mathrm{O}_{2}$ peak met all criteria for a pulmonary vascular limitation. ${ }^{15}$ The 2 others had low HR reserve and increased values for $\mathrm{V}_{E}^{\prime} / \mathrm{V}^{\prime} \mathrm{CO}_{2}$ at the anaerobic threshold (38.3 and 45.8, respectively). In view of normal values for $\mathrm{V}^{\prime} \mathrm{O}_{2}$ at the anaerobic threshold $(66 \%$ and $66 \%$, respectively) and $\mathrm{O}_{2}$ pulse ( $90 \%$ and $82 \%$, respectively), these patients appeared primarily limited by increased $\mathrm{V}_{\mathrm{d}} / \mathrm{V}_{\mathrm{t}}(0.59$ and 0.47 , respectively).

\section{CPET During Right Heart Catheterization}

Baseline hemodynamic characteristics at rest are presented in Table 3. When the generally accepted, ageindependent cut-off for PVR at rest $\left(240 \text { dynes } \cdot \mathrm{s} \cdot \mathrm{cm}^{-5}\right)^{16}$ was used, PVR was normal in all patients in whom the PCWP could be measured reliably $(\mathrm{n}=12$; all PCWP $<15 \mathrm{~mm} \mathrm{Hg}$ ). Mean pulmonary vascular compliance 
TABLE 3. Preoperative invasive CPET characteristics

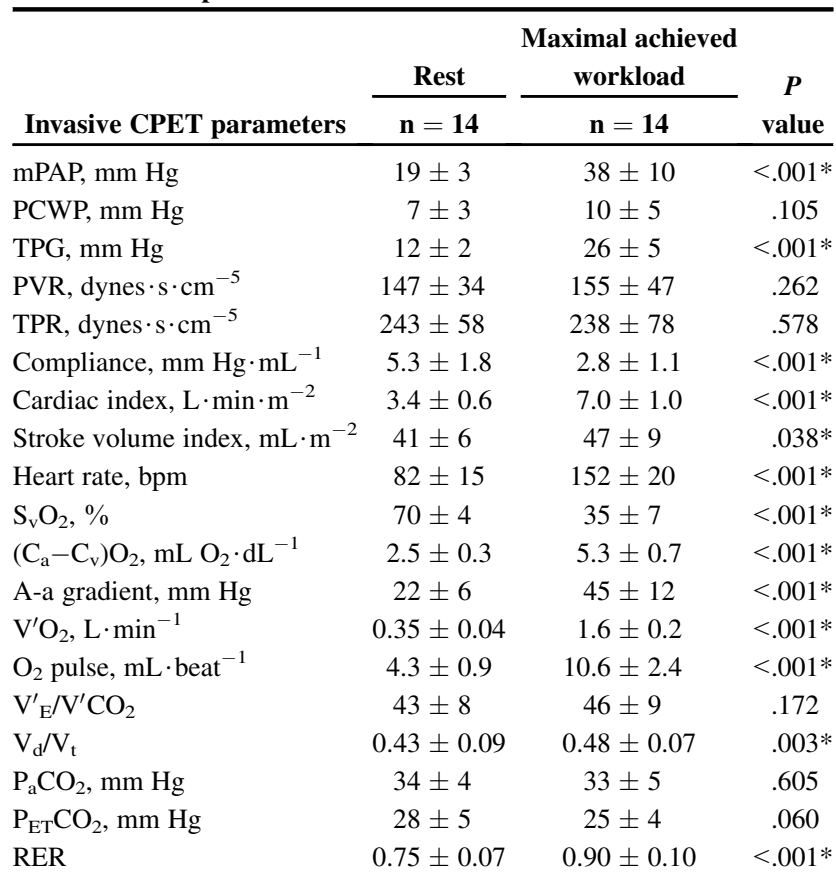

PCWP and PVR (at rest $\mathrm{n}=12$ and at exercise $\mathrm{n}=10$ ). Data presented as mean \pm standard deviation. $C P E T$, Cardiopulmonary exercise testing; $m P A P$, mean pulmonary arterial pressure; $P C W P$, pulmonary capillary wedge pressure; $T P G$, transpulmonary pressure gradient; $P V R$, pulmonary vascular resistance; $T P R$, total pulmonary vascular resistance; $b p m$, beats per minute; $S_{v} O_{2}$, mixed venous oxygen saturation; $\left(\mathrm{C}_{a}-\mathrm{C}_{v}\right) \mathrm{O}_{2}$, arterial and venous oxygen content difference; $A$-a gradient, alveolar and arterial oxygen pressure difference; $V^{\prime} O_{2}$, oxygen consumption; $\mathrm{O}_{2}$ pulse, oxygen pulse; $V^{\prime}{ }_{E} / V^{\prime} \mathrm{CO}_{2}$, ventilatory equivalent for carbon dioxide; $V_{d} / V_{t}$, dead-space ventilation; $P_{a} \mathrm{CO}_{2}$, arterial carbon dioxide tension; $P_{E T} \mathrm{CO}_{2}$, end-tidal carbon dioxide pressure; $R E R$, respiratory exchange ratio. $* P<.05$.

at rest was $5.3 \pm 1.8 \mathrm{~mL} \cdot \mathrm{mm} \mathrm{Hg}^{-1}$ (normal range: $\left.5-12 \mathrm{~mL} \cdot \mathrm{mm} \mathrm{Hg}^{-1}\right) .{ }^{17}$

All patients performed at 25-, 50-, and 75-Watt intervals, 8 patients also at a 90 - to 105 -Watt interval, and 1 patient at $125 \mathrm{Watt}$ as well. At maximal workload, all patients reached a HR $>80 \%$ of their maximum CPET-assessed HR; and, their respiratory exchange ratio remained below 1.0.

Hemodynamic responses at exercise are summarized in Table 3. Mean mPAP increased significantly during exercise. Also, mean cardiac index and the mean SV index significantly increased. Mean PCWP $(\mathrm{n}=10)$ remained $<15 \mathrm{~mm} \mathrm{Hg}$ in all but 1 patient. Mean total pulmonary vascular resistance (mPAP-CO) decreased, whereas mean PVR showed a small, nonsignificant increase $(\mathrm{n}=10)$. Mean mixed-venous oxygen saturation decreased remarkably and, in parallel, the arterial-mixed venous oxygen content difference increased significantly. The pulmonary vascular compliance, used as parameter of RV afterload, decreased significantly. Mean $\mathrm{V}_{\mathrm{d}} / \mathrm{V}_{\mathrm{t}}$ showed a nonphysiologic increase. In line, the $\mathrm{V}_{\mathrm{E}}^{\prime} / \mathrm{V}^{\prime} \mathrm{CO}_{2}$ at maximal workload was elevated in all patients, that is, above 34 .

Individual responses are shown in Figures 1 and 2. During exercise, mPAP increased in all patients, and
mPAP $>30 \mathrm{~mm} \mathrm{Hg}$ was observed in 11 of 14 patients (Figure 1,A). Also, the cardiac index increased in all patients; however, 2 patients with $\mathrm{mPAP}>30 \mathrm{~mm} \mathrm{Hg}$ had a negative SV index response (Figure $1, B$ ). The pulmonary vascular compliance decreased in 13 of 14 patients (Figure $2, B$ ). In all patients, $\mathrm{V}_{\mathrm{d}} / \mathrm{V}_{\mathrm{t}}$ at rest was increased, and in 11 of 14 we observed a significant, nonphysiological increase upon exercise $(P=.003$; Figure $2, C)$.

The mPAP-CO relationship showed a mean slope of $2.7 \pm 1.2 \mathrm{~mm} \mathrm{Hg} / \mathrm{min} / \mathrm{L} ; 7$ of 14 patients had a slope $>3.0 \mathrm{~mm} \mathrm{Hg} / \mathrm{min} / \mathrm{L}$ (Figure 3). ${ }^{12}$ In patients with a slope $>3.0 \mathrm{~mm} \mathrm{Hg} \cdot \min \cdot \mathrm{L}^{-1}$, mean $\mathrm{V}_{\mathrm{d}} / \mathrm{V}_{\mathrm{t}}$ at maximal workload was significantly greater $(0.52 \pm 0.06$ vs $0.43 \pm 0.05$; $P=.005)$. The mean pulmonary vascular compliance at maximal workload was significantly lower in these patients $(2.1 \pm 0.7$ vs $3.6 \pm 0.7 \mathrm{~mm} \mathrm{Hg} / \mathrm{mL} ; P=.003)$. Moreover, the compliance showed a highly significant inverse correlation with the mPAP-CO slope $(\mathrm{r}=-0.738$; $P=.004)$. Also, the mPAP-CO slope correlated with $\mathrm{V}_{\mathrm{d}} / \mathrm{V}_{\mathrm{t}}(\mathrm{r}=0.586 ; P=.028)$ and $\mathrm{V}_{\mathrm{E}}^{\prime} / \mathrm{V}^{\prime} \mathrm{CO}_{2}(\mathrm{r}=0.626$; $P=.017)$ at maximal workload, as well as with the CPET-assessed slope of the $\mathrm{V}^{\prime}{ }_{E} / \mathrm{V}^{\prime} \mathrm{CO}_{2}$ relationship $(\mathrm{r}=0.580 ; P=.030)$.

\section{Effect of PEA}

Of the 14 patients with CTED screened for exerciseinduced $\mathrm{PH}, 9$ patients subsequently also underwent PEA. Because their mPAP during exercise stayed within normal range, 3 patients were not considered candidates for PEA. The 2 other patients refused the offered surgery. None of the operated patients died, and postoperative course was unremarkable in all.

One year after PEA (Table 4), New York Heart Association functional class had improved from class II or III to class I in all patients. Also, mean peak workload and mean $\mathrm{V}^{\prime} \mathrm{O}_{2}$ peak had increased, and the improvements observed tended to reach statistical significance $(P<.09)$. Moreover, the $\mathrm{O}_{2}$ pulse had increased significantly, whereas peak HR had decreased, and the HR response during exercise had decreased significantly. Also, $\mathrm{V}_{\mathrm{E}}^{\prime} / \mathrm{V}^{\prime} \mathrm{CO}_{2}$ both at the anaerobic threshold and at peak exercise had decreased significantly, without a concomitant change in maximal ventilation. Lastly, the slope of the $\mathrm{V}^{\prime}{ }_{\mathrm{E}} / \mathrm{V}^{\prime} \mathrm{CO}_{2}$ relationship had decreased significantly, and on average had normalized.

\section{DISCUSSION}

In the present study we demonstrated abnormal pulmonary vascular responses to exercise in patients with CTED, that is, a steep mPAP-CO slope and a decreased pulmonary vascular compliance. The circulatory responses were correlated strongly with parameters reflecting $\mathrm{V}_{\mathrm{d}} / \mathrm{V}_{\mathrm{t}}$ and ventilatory (in)efficiency. One year after PEA, we observed a clinically significant improvement in exercise capacity, which was related to significant improvements 

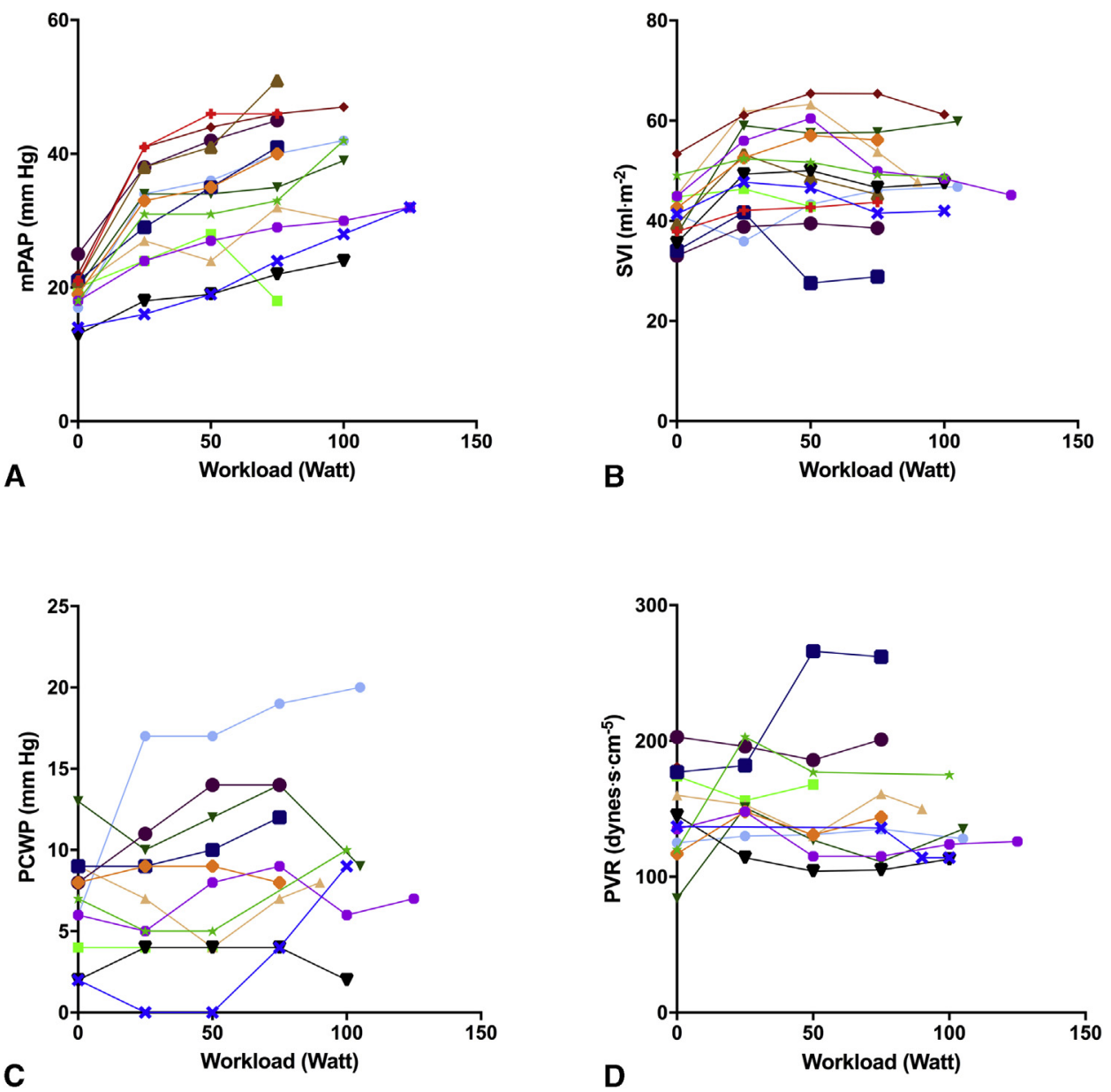

FIGURE 1. Invasive CPET data presented at increasing workloads. A, $m P A P$, mean pulmonary arterial pressure; (B) $S V I$, stroke volume index; (C) $P C W P$, pulmonary capillary wedge pressure; (D) $P V R$, pulmonary vascular resistance.

in CPET-derived parameters pointing to restoration of the right ventricle (RV)-SV response and ventilatory efficiency.

In healthy subjects during exercise, an age- and exercisedependent small increase in mPAP and PCWP is observed, resulting in a slight decrease in PVR and a more pronounced decrease in total pulmonary vascular resistance. ${ }^{18}$ The limited increase in mPAP is the consequence of pulmonary vascular recruitment and dilatation; in line, in healthy individuals during exercise, the pulmonary vascular compliance was demonstrated to increase. ${ }^{13}$ As a consequence, a flat mPAP-CO slope is observed. ${ }^{19}$ In contrast, however, in a recent study, Claessen and colleagues ${ }^{20}$ observed a decrease in the pulmonary vascular compliance during exercise even in healthy individuals. In comparison with the patients with CTED studied here, however, the pulmonary vascular compliance, both at rest and during exercise, appeared greater in these individuals. In CTE with and without pulmonary hypertension $[\mathrm{CTE}(\mathrm{PH})]$, recruitment and dilatation is hampered because of the chronic thromboembolic obstruction of the pulmonary vasculature and/or the secondary small vessel arteriopathy that can be observed in the nonobstructed vessels of these patients. ${ }^{1,21}$ Therefore, like in pulmonary arterial hypertension, increases in $\mathrm{CO}$ during exercise will result in steep pressure-flow slopes. ${ }^{22}$

In a study on $\mathrm{PH}$, including inoperable CTEPH, Blumberg and colleagues ${ }^{23}$ showed that the mPAP-CO slopes were increased and served as predictor of survival. In a small post-PEA CTEPH cohort, in patients with normalized pulmonary hemodynamics at rest but persistent exerciseinduced shortness of breath, Bonderman and colleagues ${ }^{13}$ observed during exercise a decreased pulmonary vascular compliance; moreover, the decreased compliance was a strong predictor of the exercise intolerance. Compared with the healthy controls studied, in the patients with CTEPH, Claessen and colleagues ${ }^{20}$ observed a strikingly reduced compliance at rest already. Compared with these data, at rest, the compliance in the patients with CTED showed values between the patients with CTEPH and the healthy controls, likewise, the change in compliance at exercise.

Recently, it has been suggested to use the mPAP-CO slope to redefine exercise-induced $\mathrm{PH}$; for this, an 

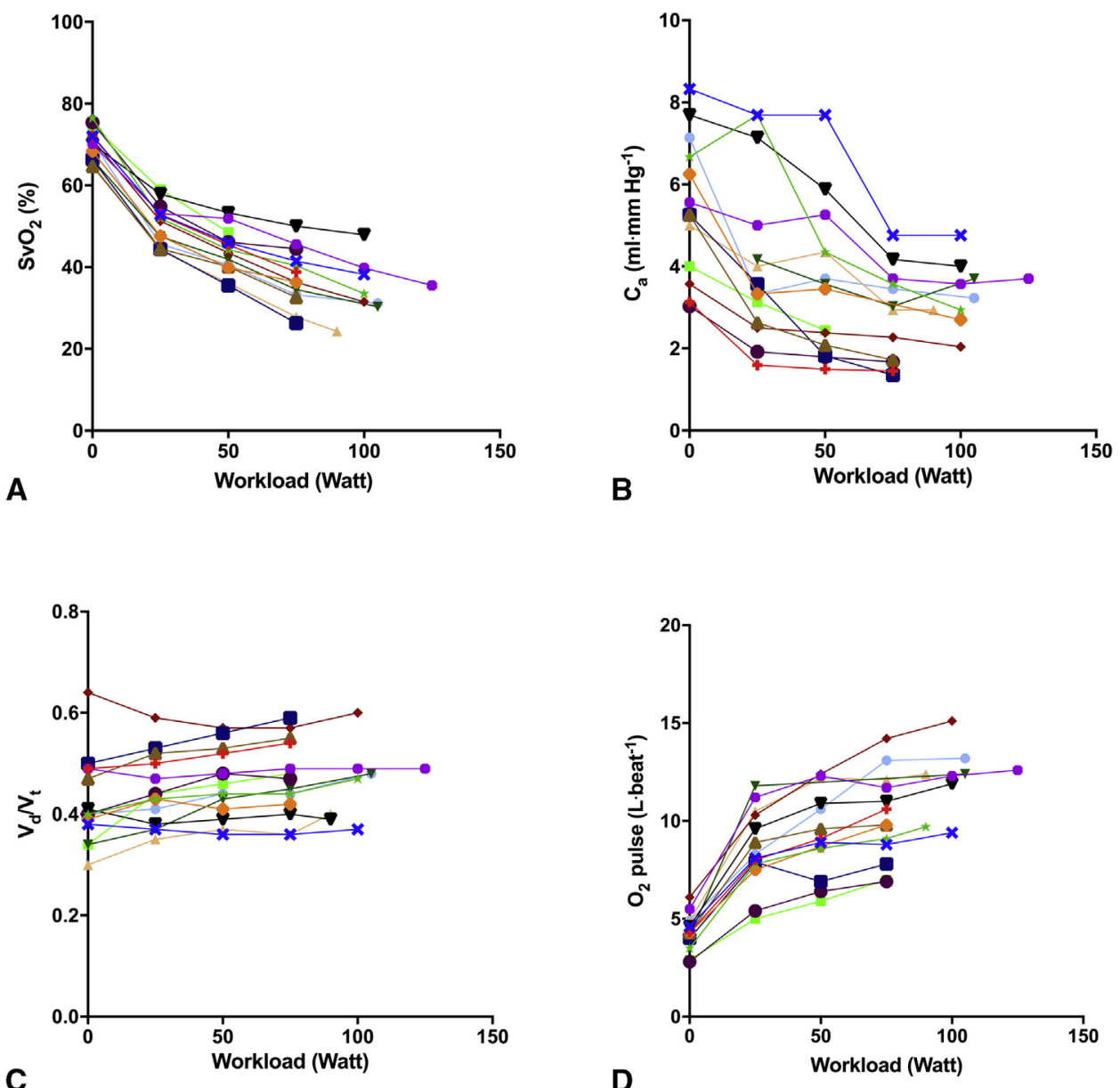

FIGURE 2. Invasive CPET data presented at increasing workloads. A, $\mathrm{Sv}_{2}$, mixed-venous oxygen saturation; (B) $C_{a}$, pulmonary arterial compliance; (C) $V_{d} / V_{t}$, dead-space ventilation; (D) $O_{2}$ pulse, oxygen pulse.

mPAP-CO slope $>3.0 \mathrm{~mm} \mathrm{Hg} / \mathrm{min} / \mathrm{L}$ was proposed as cut-off level. ${ }^{12,24}$ Using this definition, we observed an increased mPAP-CO slope in half of the patients studied. Moreover, the pulmonary vascular compliance at rest appeared to be decreased, ${ }^{20}$ and it showed a further decrease in all but 1 patient. In addition, the mPAP-CO slope and the pulmonary vascular compliance showed a strong inverse correlation, both indicating that vascular recruitment and dilatation in these patients with CTED was seriously hampered. Like in healthy individuals, only a small increase in PCWP was observed. ${ }^{18}$

Therefore, an increase in left atrial pressure during exercise cannot explain the increase in mPAP observed here. On the basis of the hemodynamic responses observed in our patients, we conclude that most patients had indeed a compromised pulmonary vascular response during exercise; the concomitant increase in RV afterload generally is considered a major determinant of the exercise limitation observed in patients with $\mathrm{CTE}(\mathrm{PH}){ }^{13,23,25}$

In CTEPH, exercise is limited primarily by the inability of the heart to sufficiently increase pulmonary blood flow as the result of a decreased RV-SV response, considered the consequence of the abnormal pulmonary vascular response $^{26}$; however, next to an impaired cardiac response, ventilation-perfusion mismatching caused by the thromboembolic obstruction and/or the secondary arteriopathy also is likely to play a role in the pathophysiology of the exercise limitation observed in CTEPH. In CTE(PH), a decreased ventilatory efficiency during exercise is observed, ${ }^{14,15}$ and parameters of increased $\mathrm{V}_{\mathrm{d}} / \mathrm{V}_{\mathrm{t}}$ correlate with the hemodynamic severity of disease. ${ }^{8,15}$ During exercise, as blood flow fails to perfuse the ventilated lung, $\mathrm{V}_{\mathrm{d}} / \mathrm{V}_{\mathrm{t}}$ increases further; to compensate for this, the patient's ventilatory requirement increases, leading to dyspnea.

In previous studies in CTEPH, increased $\mathrm{V}_{\mathrm{d}} / \mathrm{V}_{\mathrm{t}}$ was shown to correlate with the decreased exercise capacity observed in these patients. ${ }^{8,27,28} \mathrm{~V}_{\mathrm{d}} / \mathrm{V}_{\mathrm{t}}$ at rest was increased in all patients studied here. Whereas during exercise in healthy individuals $\mathrm{V}_{\mathrm{d}} / \mathrm{V}_{\mathrm{t}}$ decreases, in all of our patients a further increase was observed. The ventilatory equivalent for $\mathrm{CO}_{2}\left(\mathrm{~V}_{\mathrm{E}}^{\prime} / \mathrm{V}^{\prime} \mathrm{CO}_{2}\right)$ at the anaerobic threshold and the $\mathrm{V}_{\mathrm{E}}^{\prime} / \mathrm{V}^{\prime} \mathrm{CO}_{2}$ slope are 


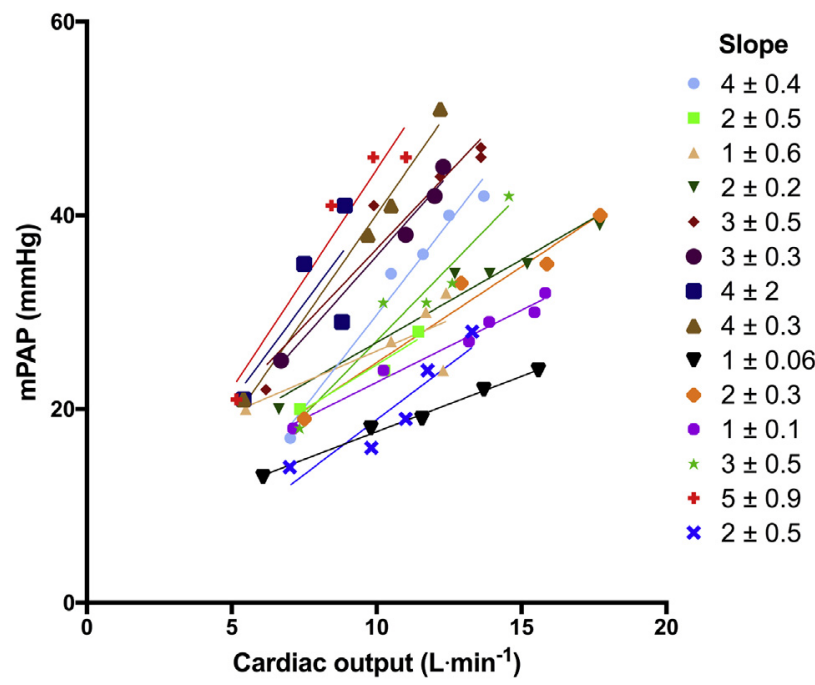

FIGURE 3. Mean arterial pressure and cardiac output relation of the 14 patients with CTED with corresponding slopes. Data presented as mean \pm standard deviation. $m P A P$, Mean pulmonary artery pressure.

considered to reflect ventilatory (in)efficiency. In CTE(PH), ventilation is increased excessively in relation to the metabolic rate ${ }^{29}$; this is at least in part the consequence of increased $\mathrm{V}_{\mathrm{d}} / \mathrm{V}_{\mathrm{t}}$; however, exercise-induced hypoxemia, sympathetic overstimulation, and/or stimulation of pressure receptors in the pulmonary vascular bed also may play a role. $^{15,30,31}$ In the patients with CTED studied here, however, the arterial carbon dioxide pressure was greater than the end-tidal carbon dioxide pressure, suggesting that the ventilatory inefficiency observed was indeed most likely due to the increased $\mathrm{V}_{\mathrm{d}} / \mathrm{V}_{\mathrm{t}}$.

Using CPET, 1 year after PEA we observed an increase in maximal workload, peak oxygen consumption, and peak $\mathrm{O}_{2}$ pulse. In contrast, maximal HR and the HR response decreased despite the increased maximal physical performance. These observations point to a postoperative improvement of the RV-SV response during exercise, which was shown before in patients with CTEPH by use of cardiac magnetic resonance imaging. ${ }^{26}$ The improvement in RV-SV response is the consequence of the PEA-associated decrease in $\mathrm{RV}$ afterload, that is, PEA improves $\mathrm{CO}$ by improving the $\mathrm{RV}-\mathrm{SV}$ response, thereby decreasing the need for a chronotropic (HR) response. ${ }^{32}$ In CTE(PH), the decrease in $\mathrm{O}_{2}$ pulse, that is, $\mathrm{V}^{\prime} \mathrm{O}_{2} / \mathrm{HR}$, observed is in major part the consequence of an impaired RV-SV response, and the postoperative increase in $\mathrm{O}_{2}$ pulse observed in our patients is likely to reflect its restoration. However, it cannot be excluded that, at least in minor part, the improvement also was caused by a more-efficient oxygen extraction by the peripheral muscles because of a training effect by an overall increased physical fitness.

The improvement in RV afterload is the direct consequence of the PEA-induced restoration of the pulmonary
TABLE 4. Functional parameters and CPET data before and $1 \mathrm{y}$ after PEA

\begin{tabular}{|c|c|c|c|}
\hline & Pre-PEA & 1 y post-PEA & $\boldsymbol{P}$ \\
\hline Functional parameters & $\mathbf{n}=\mathbf{9}$ & $\mathbf{n}=\mathbf{9}$ & value \\
\hline 6-MWD, m & $517 \pm 19$ & $548 \pm 21$ & .096 \\
\hline BORG (6-MWT) at rest & $1.1 \pm 0.4$ & $0.6 \pm 0.3$ & .128 \\
\hline BORG (6-MWT) at end of exercise & $3.9 \pm 0.5$ & $2.2 \pm 0.5$ & $.025^{*}$ \\
\hline Heart rate at rest (6-MWT), bpm & $82 \pm 5$ & $79 \pm 3$ & .391 \\
\hline $\begin{array}{l}\text { Heart rate end of exercise } \\
(6-\mathrm{MWT}), \mathrm{bpm}\end{array}$ & $128 \pm 7$ & $124 \pm 5$ & .412 \\
\hline $\mathrm{SaO}_{2}$ rest (6-MWT), \% & $97 \pm 0.8$ & $96 \pm 0.5$ & .659 \\
\hline $\mathrm{SaO}_{2}$ exercise (6-MWT), \% & $92 \pm 0.8$ & $93 \pm 0.8$ & .434 \\
\hline NYHA functional class I/II/III & $0 / 6 / 3$ & $9 / 0 / 0$ & $.006 *$ \\
\hline \multicolumn{4}{|l|}{ Pulmonary function } \\
\hline $\mathrm{VC}, \%$ of predicted & $103 \pm 4$ & $102 \pm 3$ & .765 \\
\hline $\mathrm{FEV}_{1}, \%$ of predicted & $100 \pm 4$ & $96 \pm 4$ & .230 \\
\hline $\mathrm{FEV}_{1} / \mathrm{FVC}$ & $0.78 \pm 0.04$ & $0.75 \pm 0.04$ & .106 \\
\hline TLCO, $\%$ of predicted & $65 \pm 3$ & $66 \pm 4$ & .434 \\
\hline TLCO/VA, $\%$ of predicted & $82 \pm 4$ & $82 \pm 3$ & .063 \\
\hline \multicolumn{4}{|l|}{ CPET parameters } \\
\hline Peak workload, Watt & $127 \pm 12$ & $140 \pm 14$ & .062 \\
\hline $\mathrm{V}^{\prime} \mathrm{O}_{2}$ peak, $\mathrm{L} \cdot \mathrm{min}^{-1}$ & $1.8 \pm 0.1$ & $2.1 \pm 0.2$ & .087 \\
\hline $\mathrm{V}^{\prime} \mathrm{O}_{2}$ peak, $\%$ predicted & $97 \pm 5$ & $110 \pm 6$ & .067 \\
\hline $\mathrm{V}^{\prime} \mathrm{O}_{2} @ \mathrm{AT}, \mathrm{L} \cdot \mathrm{min}^{-1}$ & $1.3 \pm 0.1$ & $1.5 \pm 0.2$ & .192 \\
\hline $\mathrm{V}^{\prime} \mathrm{O}_{2} @ \mathrm{AT}, \%$ of $\mathrm{V}^{\prime} \mathrm{O}_{2}$ peak & $67 \pm 3$ & $78 \pm 6$ & .157 \\
\hline Peak $V^{\prime} E, L \cdot \min ^{-1}$ & $87 \pm 6$ & $85 \pm 8$ & .590 \\
\hline Ventilatory reserve, $\%$ & $14 \pm 4$ & $13 \pm 4$ & .844 \\
\hline Peak HR, bpm & $159 \pm 7$ & $155 \pm 7$ & .130 \\
\hline Heart rate reserve, bpm & $9 \pm 8$ & $12 \pm 8$ & .233 \\
\hline Heart rate response, bpm & $81 \pm 4$ & $72 \pm 6$ & $.003 *$ \\
\hline $\mathrm{V}_{\mathrm{E}}^{\prime} / \mathrm{V}^{\prime} \mathrm{CO}_{2} @ \mathrm{AT}$ & $39 \pm 2$ & $34 \pm 2$ & $.008 *$ \\
\hline $\mathrm{V}_{\mathrm{E}}^{\prime} / \mathrm{V}^{\prime} \mathrm{CO}_{2}$ at peak & $47 \pm 3$ & $40 \pm 3$ & $.013^{*}$ \\
\hline $\mathrm{V}^{\prime}{ }_{\mathrm{E}} / \mathrm{V}^{\prime} \mathrm{CO}_{2}$ slope & $38 \pm 4$ & $33 \pm 7$ & $.014 *$ \\
\hline Peak $\mathrm{O}_{2}$ pulse, $\mathrm{mL} \cdot$ beat $^{-1}$ & $12 \pm 1$ & $13 \pm 1$ & $.027 *$ \\
\hline Peak $\mathrm{O}_{2}$ pulse, $\%$ predicted & $101 \pm 6$ & $114 \pm 8$ & $.025^{*}$ \\
\hline$\Delta \mathrm{V}^{\prime} \mathrm{O}_{2} / \Delta$ Wattage, $\mathrm{L} \cdot \mathrm{min} \cdot \mathrm{Watt}^{-1}$ & $10 \pm 1$ & $10 \pm 1$ & .283 \\
\hline Peak $\mathrm{O}_{2}$ saturation, $\%$ & $92 \pm 2$ & $95 \pm 1$ & .103 \\
\hline
\end{tabular}

Data presented as mean \pm standard error of mean. PEA, Pulmonary endarterectomy 6-MWD, 6-minute walk distance; $B O R G$, BORG score of perceived dyspnoea; 6-MWT, 6-minute walk test; $\mathrm{bpm}$, beats per minute; $\mathrm{SaO}_{2}$, transcutaneous oxygen saturation; NYHA, New York Heart Association; $V C$, vital capacity; $F E V_{l}$, forced expiratory volume in $1 \mathrm{~s} ; F V C$, forced vital capacity; $T L C O$, transfer factor for carbon monoxide; $V A$, alveolar volume; $C P E T$, cardiopulmonary exercise testing; $V^{\prime} O_{2}$ peak, peak oxygen consumption; $V^{\prime} O_{2} @ A T$, oxygen consumption at the anaerobic threshold; $V_{E}^{\prime}$, minute ventilation; $\mathrm{HR}$, heart rate; $V^{\prime} \mathrm{CO}_{2}$, carbon dioxide production; $V^{\prime} \mathrm{CO}_{2} @ A T$, ventilatory equivalent for carbon dioxide at the anaerobic threshold; $O_{2}$ pulse, oxygen pulse; $\Delta V^{\prime} O_{2} / \Delta$ Wattage, slope of the oxygen consumption and workload relation; Peak $\mathrm{O}_{2}$ saturation, transcutaneous oxygen saturation at peak exercise level. $* P<.05$.

blood flow. In parallel, as we also observed in our patients, $\mathrm{V}_{\mathrm{d}} / \mathrm{V}_{\mathrm{t}}$ decreases. ${ }^{33}$ Therefore, restoration of the patency of the pulmonary vasculature not only resulted in an improvement in RV-SV response due to a reduction in RV afterload but also in an improvement in ventilatory efficiency due to a restoration of ventilation-perfusion mismatching, that is, a decrease in $\mathrm{V}_{\mathrm{d}} / \mathrm{V}_{\mathrm{t}}{ }^{8}$

This is the first in-depth study on the pathophysiology of the exercise limitation that can be observed in patients with 
CTED; moreover, the CPET follow-up at 1 year was very complete. Some limitations, however, also need to be addressed. First, the number of patients studied was relatively low. Second, for ethical reasons, we did not perform a repeat invasive exercise test 1 year after PEA. Therefore, we were unable to draw final conclusions on the extent of restoration of the pressure-flow slopes and pulmonary vascular compliance in our patients. Also, the question has been asked whether surgery should be offered to these patients, given the considerable perioperative risk of PEA even when performed in an expert center ${ }^{3,34}$ and the fact that conservative management appears a safe alternative choice for these patients. ${ }^{2}$ Given their significant symptomatology in the context of an abnormal hemodynamic response during exercise, we offered surgery to (part of) the patients studied here. The postoperative course was unremarkable in all patients, and they all showed a symptomatic improvement in the context of significantly improved physiologic responses upon exercise. Therefore, in carefully selected patients with symptomatic CTED, performing PEA seems beneficial, outweighing the probably significantly lower risk for morbidity and mortality in this subgroup of patients with CTED; the surgery, however, should only be performed in expert centers. $^{35}$

In summary, we conclude that our observations point to a hampered pulmonary vascular response and decreased ventilatory efficiency as underlying pathophysiological mechanisms to explain the exercise limitation observed in patients with CTED. The clinically significant symptomatic improvement after surgery was shown to be related to significant improvements in both circulatory and ventilatory responses indicative for an improved RV-SV during exercise and ventilatory efficiency.

\section{Conflict of Interest Statement}

Authors have nothing to disclose with regard to commercial support.

C.K. and P.B. had full access to all of the data in the study and take responsibility for the integrity of the data and the accuracy of the data analysis. C.K., M.P., H.R., R.S., J.K., R.T., P.I.B., and P.B. contributed substantially to the study design, data collection, data analysis and interpretation, and the writing of the manuscript. Moreover, Prof. A.H. Zwinderman, PhD, and D. van Rooijen, $\mathrm{PhD}$, are acknowledged for their statistical advice.

\section{References}

1. Fedullo PF, Auger WR, Kerr KM, Rubin LJ. Chronic thromboembolic pulmonary hypertension. $N$ Engl J Med. 2001;345:1465-72.

2. Riedel M, Stanek V, Widimsky J, Prerovsky I. Longterm follow-up of patients with pulmonary thromboembolism. Late prognosis and evolution of hemodynamic and respiratory data. Chest. 1982;81:151-8.

3. Madani MM, Auger WR, Pretorius V, Sakakibara N, Kerr KM, Kim NH, et al. Pulmonary endarterectomy: recent changes in a single institution's experience of more than 2,700 patients. Ann Thorac Surg. 2012;94:97-103.
4. Archibald CJ, Auger WR, Fedullo PF. Outcome after pulmonary thromboendarterectomy. Semin Thorac Cardiovasc Surg. 1999;11:164-71.

5. Reesink HJ, Van der Plas MN, Verhey NE, van Steenwijk RP, Kloek JJ, Bresser P. Six-minute walk distance as parameter of functional outcome after pulmonary endarterectomy for chronic thromboembolic pulmonary hypertension. J Thorac Cardiovasc Surg. 2007;133:510-6.

6. Dartevelle P, Fadel E, Mussot S, Chapelier A, Herve P, de Perrot M, et al. Chronic thromboembolic pulmonary hypertension. Eur Respir J. 2004;23: 637-48.

7. Taboada D, Pepke-Zaba J, Jenkins DP, Berman M, Treacy CM, Cannon JE, et al. Outcome of pulmonary endarterectomy in symptomatic chronic thromboembolic disease. Eur Respir J. 2014;44:1635-45.

8. Van der Plas MN, Reesink HJ, Roos CM, van Steenwijk RP, Kloek JJ, Bresser P. Pulmonary endarterectomy improves dyspnea by the relief of dead space ventilation. Ann Thorac Surg. 2010;89:347-52.

9. Hardziyenka M, Reesink HJ, Bouma BJ, de Bruin-Bon HA, Campian ME, Tanck MW, et al. A novel echocardiographic predictor of in-hospital mortality and mid-term haemodynamic improvement after pulmonary endarterectomy for chronic thrombo-embolic pulmonary hypertension. Eur Heart J. 2007;28: 842-9.

10. Barst RJ, McGoon M, Torbicki A, Sitbon O, Krowka MJ, Olschewski H, et al. Diagnosis and differential assessment of pulmonary arterial hypertension. J Am Coll Cardiol. 2004;43:40S-7S.

11. ATS/ACCP Statement on cardiopulmonary exercise testing. Am J Respir Crit Care Med. 2003; 167:211-77.

12. Naeije R, Vanderpool R, Dhakal BP, Saggar R, Saggar R, Vachiery JL, et al. Exercise-induced pulmonary hypertension: physiological basis and methodological concerns. Am J Respir Crit Care Med. 2013;187:576-83.

13. Bonderman D, Martischnig AM, Vonbank K, Nikfardjam M, Meyer B, Heinz G, et al. Right ventricular load at exercise is a cause of persistent exercise limitation in patients with normal resting pulmonary vascular resistance after pulmonary endarterectomy. Chest. 2011;139:122-7.

14. Wasserman K, Hansen JE, Sue DY, Stringer WW, Whipp BJ. Principles of Exercise Testing and Interpretation. 4th ed. Philadelphia: Lippincott Williams \& Wilkins; 2005.

15. Sun XG, Hansen JE, Oudiz RJ, Wasserman K. Exercise pathophysiology in patients with primary pulmonary hypertension. Circulation. 2001;104:429-35.

16. McLaughlin VV, Archer SL, Badesch DB, Barst RJ, Farber HW, Lindner JR, et al. ACCF/AHA 2009 expert consensus document on pulmonary hypertension a report of the American College of Cardiology Foundation Task Force on Expert Consensus Documents and the American Heart Association developed in collaboration with the American College of Chest Physicians; American Thoracic Society, Inc.; and the Pulmonary Hypertension Association. J Am Coll Cardiol. 2009;53:1573-619.

17. Slife DM, Latham RD, Sipkema P, Westerhof N. Pulmonary arterial compliance at rest and exercise in normal humans. Am J Physiol. 1990;258:H1823-8.

18. Kovacs G, Olschewski A, Berghold A, Olschewski H. Pulmonary vascular resistances during exercise in normal subjects: a systematic review. Eur Respir J. 2012;39:319-28.

19. Lewis GD, Bossone E, Naeije R, Grunig E, Saggar R, Lancellotti P, et al. Pulmonary vascular hemodynamic response to exercise in cardiopulmonary diseases. Circulation. 2013;128:1470-9.

20. Claessen G, La GA, Dymarkowski S, Claus P, Delcroix M, Heidbuchel H Pulmonary vascular and right ventricular reserve in patients with normalized resting hemodynamics after pulmonary endarterectomy. J Am Heart Assoc. 2015;4:e001602.

21. Hoeper MM, Mayer E, Simonneau G, Rubin LJ. Chronic thromboembolic pulmonary hypertension. Circulation. 2006;113:2011-20.

22. Tolle JJ, Waxman AB, Van Horn TL, Pappagianopoulos PP, Systrom DM Exercise-induced pulmonary arterial hypertension. Circulation. 2008;118: 2183-9.

23. Blumberg FC, Arzt M, Lange T, Schroll S, Pfeifer M, Wensel R. Impact of right ventricular reserve on exercise capacity and survival in patients with pulmonary hypertension. Eur J Heart Fail. 2013;15:771-5.

24. Herve P, Lau EM, Sitbon O, Savale L, Montani D, Godinas L, et al. Criteria for diagnosis of exercise pulmonary hypertension. Eur Respir J. 2015; 46:728-37.

25. McCabe C, White PA, Hoole SP, Axell RG, Priest AN, Gopalan D, et al. Right ventricular dysfunction in chronic thromboembolic obstruction of the pulmonary artery: a pressure-volume study using the conductance catheter. J Appl Physiol (1985). 2014;116:355-63. 
26. Surie S, Van der Plas MN, Marcus JT, Kind T, Kloek JJ, Vonk-Noordegraaf A, et al. Effect of pulmonary endarterectomy for chronic thromboembolic pulmonary hypertension on stroke volume response to exercise. Am J Cardiol. 2014; 114:136-40.

27. McCabe C, Deboeck G, Harvey I, Ross RM, Gopalan D, Screaton N, et al. Inefficient exercise gas exchange identifies pulmonary hypertension in chronic thromboembolic obstruction following pulmonary embolism. Thromb Res. 2013;132:659-65.

28. Zhai Z, Murphy K, Tighe H, Wang C, Wilkins MR, Gibbs JS, et al. Differences in ventilatory inefficiency between pulmonary arterial hypertension and chronic thromboembolic pulmonary hypertension. Chest. 2011;140:1284-91.

29. Melot C, Naeije R. Pulmonary vascular diseases. Compr Physiol. 2011;1: 593-619.

30. Velez-Roa S, Ciarka A, Najem B, Vachiery JL, Naeije R, van de Borne P. Increased sympathetic nerve activity in pulmonary artery hypertension. Circulation. 2004;110:1308-12.

31. Wasserman K, Whipp BJ, Koyal SN, Cleary MG. Effect of carotid body resection on ventilatory and acid-base control during exercise. J Appl Physiol. 1975;39:354-8.
32. Van der Plas MN, Surie S, Reesink HJ, van Steenwijk RP, Kloek JJ, Bresser P. Longitudinal follow-up of six-minute walk distance after pulmonary endarterectomy. Ann Thorac Surg. 2011;91:1094-9.

33. Kapitan KS, Clausen JL, Moser KM. Gas exchange in chronic thromboembolism after pulmonary thromboendarterectomy. Chest. 1990;98:14-9.

34. Mayer E, Jenkins D, Lindner J, D’Armini A, Kloek J, Meyns B, et al. Surgical management and outcome of patients with chronic thromboembolic pulmonary hypertension: results from an international prospective registry. $J$ Thorac Cardiovasc Surg. 2011;141:702-10.

35. Jenkins DP, Biederman A, D'Armini AM, Dartevelle PG, Gan HL, Klepetko W et al. Operability assessment in CTEPH: Lessons from the CHEST-1 study J Thorac Cardiovasc Surg. April 12, 2016 [Epub ahead of print].

Key Words: chronic thromboembolic pulmonary hypertension, pulmonary endarterectomy, cardiopulmonary exercise test, right heart catheterization, pulmonary hypertension

\title{
EDITORIAL COMMENTARY
}

\section{Understanding pathophysiologic changes occurring in chronic thromboembolic disease}

\author{
Robert B. Cameron, MD
}

\footnotetext{
From the Division of Thoracic Surgery, Department of Surgery, David Geffen School of Medicine at UCLA; and the Division of Thoracic Surgery, Department of Surgery and Perioperative Care, West Los Angeles VA Medical Center, Los Angeles, Calif.

Disclosures: Author has nothing to disclose with regard to commercial support.

Received for publication June 20, 2016; accepted for publication June 21, 2016.

Address for reprints: Robert B. Cameron, MD, Division of Thoracic Surgery, Department of Surgery, David Geffen School of Medicine, 10780 Santa Monica Blvd, Suite 100, Los Angeles, CA 90025 (E-mail: rcameron@ stanfordalumni.org).

J Thorac Cardiovasc Surg 2016;152:771-2

$0022-5223 / \$ 36.00$

Copyright (C 2016 by The American Association for Thoracic Surgery

http://dx.doi.org/10.1016/j.jtcvs.2016.06.031
}

The pathophysiologic processes involved in the development of chronic pulmonary thromboembolic disease (CTED) from acute pulmonary embolism are poorly understood. ${ }^{1,2}$ In the most simplistic physiologic terms, one or more pulmonary emboli fail to resolve through fibrinolysis, leading to chronic obstruction of the pulmonary vascular bed and resulting in increasing right heart failure. There is substantial evidence, however, that the process may not be quite so simple. First, if simple obstruction were the only issue, pulmonary endarterectomy (PEA) should reliably lead to improvement or resolution of pulmonary hypertension in all cases-in fact, however, this does not occur. Some patients have persistent or residual pulmonary hypertension after PEA, and these patients face higher perioperative mortality as well as worse quality of life after

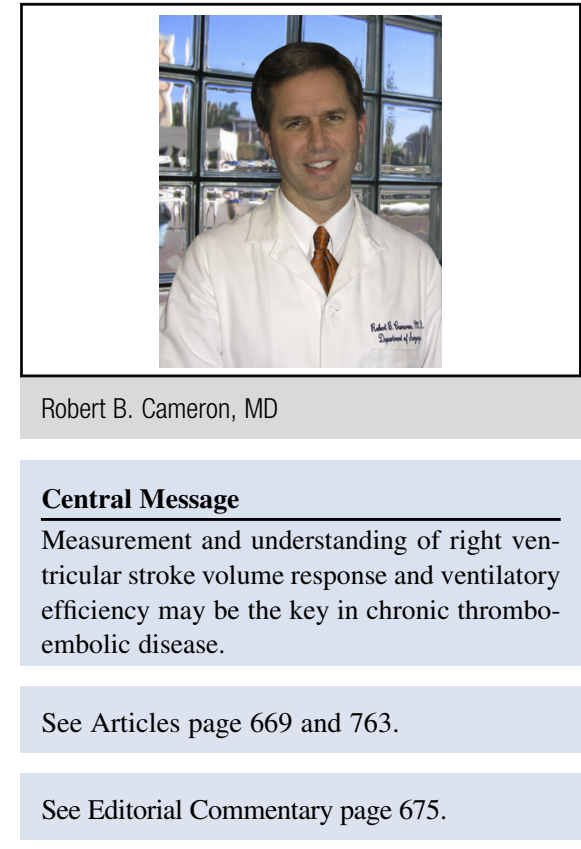

surgery. ${ }^{2,3}$ Jamieson and colleagues ${ }^{4}$ noted from their very large experience that patients with postoperative pulmonary vascular resistance greater than 500 dyne $\cdot \mathrm{s}^{-1} \cdot \mathrm{cm}^{-5}$ had a mortality as high as $30.6 \%$, primarily as a result of residual pulmonary hypertension. ${ }^{4}$ The only preoperative factor 